\title{
Modeling Cell Movement on a Substrate WITH VARIABLE RIGIDITY
}

\author{
Arkady Voloshin \\ Department of Mechanical Engineering and Mechanics and \\ Bioengineering Program \\ Lehigh University
}

\begin{abstract}
Live cells respond to the changes of their physiological environment as well as to the mechanical stimuli occurring in and out of the cell body. It is known that cell directional motion is influenced by the substrate stiffness. A finite element modelling based on the tensegrity approach is used here to describe the biomechanical behavior of cells. The effects of substrate stiffness and prestress on strain energy of a cell are investigated by defining several substrate stiffness values and prestress values. Numerical simulations reveal that the internal elastic strain energy of the cell decreases as the substrate stiffness increases. As prestress of cell increases, the strain energy increases as well. The change of prestress value does not change behavior pattern of the strain energy: strain energy of a cell will decrease when substrate stiffness increases. These findings indicate that both cell prestress and substrate stiffness influence the cell directional movement.
\end{abstract}

\section{KEYWORDS}

cell motion, strain energy, tensegrity, modelling, substrate stiffness.

\section{INTRODUCTION}

Cell migration may be encouraged by various external to the cell factors, like chemical [1] (chemotaxis), mechanical [2] (mechanotaxis), thermal [3] (thermotaxis), electrical [4] (galvanotaxis) or topological [5] (topotaxis) to name a few. Migration requires interaction between the cell and substrate it is located on the exact mechanisms by which different environmental forces are transduced into cell biological responses are still unknown. However, in any physical environment changes of cell's geometry and motion are influenced by its physical and internal balance [6] since a cell needs to maintain its morphological stability and molecular self-assembly. Cell attached to a substrate can sense mechanical stimuli [ 7,8 ,9 ], respond the stimuli in order to keep cell's intracellular and extracellular forces in balance $[10,11]$ and regulate many important physiological and pathological processes $[12,13,14]$.

Current experimental works focus on developing and identifying the mechanism called "mechanotransduction", on the processes by which cells sense mechanical force and transduce it into a biochemical signal. Some of these studies have shown that cell movement have been influenced by substrate's rigidity [15,16]. Based on the hypothesis that a single cell can probe substrate stiffness and respond by exerting contractile forces, Lo and colleagues [15] referred to the process as "durotaxis". On the other hand, both computational $[17,18,19]$ and mathematical 
models [20] have been developed for further understanding of the biomechanical cellular responses. Computational mechanical models, especially tensegrity structures [21,22], have been widely used to model the cellular responses to environment changes.

Cell alterations in shape and structure caused by mechanical loads are critical to cell functions, such as growth, motility, differentiation, and proliferation $[23,24]$. It is also well known that the directional movement of a cell is an important component of developmental patterning, wound healing and tumor metastasis $[25,26]$. It is a critical question to understand the mechanisms by which the cells resist and react to the deformation under various physical conditions.

The forces generated within the actin cytoskeleton and applied to the extracellular matrix through focal adhesions can influence cell interaction with extracellular environment, such as cell migration and formation of focal adhesion [27,28].Cells can sense physicochemical and biochemical signals of surrounding environments that can be transmitted between cell and substrate via focal adhesions. By probing environment parameters or connecting with environment directly, cells can guide their activities, such as changing morphologies and migratory directions, due to the environmental changes. The in-vitro studies[29, 30, 31] have shown that cells cultured on substrate are influenced by substrate mechanics. Georgeset al.[29] showed that cells are able to sense the substrate rigidity since certain types of cells have less rounded shape on stiffer substrate and are more likely to exhibit as rounded shape on softer substrate. However, the study by Saezet al. [30], got the opposite results by using epithelial cells cells are likely to extend into branched morphologies on softer substrate than the same cells on stiffer substrate. Cell morphology was changing, but they migrated towards the area of larger stiffness. Recently it was shown that the chromatin plasticity in epithelial cells is dependent of the substrate stiffness [31].Previous experiments also have shown that cells tend to move towards stiffer region on certain patterned substrate, which is known as durotaxis [32].Substrate stiffness varies across cell types, from softer brain tissue to stiffer bone tissue. The differences in substrate stiffness are caused by the various substrates' components and their concentrations.

To get better understanding of these complex structures and processes, various mechanical computational models have been developed in recent decades [32,33,34,35,36,37,38]. Mechanical computational models could provide the insights into how the physical properties of the substrate or adherent cells influence cells' morphologies and movements. There are two main categories of computational models to investigate cells' responses to environmental changes: continuum approach $[32,33,34,35]$ and micro/ nanostructral approach $[33,36,37,38]$.

The first category of computational models can be defined as continuum mechanical model that includes four major different types: liquid drop model, power-law structural damping model, solid model, and biphasic model. The cells are treated as certain continuum material properties in this method. The continuum mechanical model has been used to model blood cell with cytoplasm as a viscous liquid and cortex as cortical membrane [34], to study small strain deformation characteristics of leukocytesas a linear visco elastic solid model [35] and to model single chondrocytes and their interaction with the extracellular cartilage matrix [36].

The second category of computational model is based on microstructural and nanostructural approach. This approach includes the tensegrity model, tensed cable network model, open-cell foam model and spectrin-network model for erythrocytes. The cytoskeleton is used as the main structural component in microstructural and nanostructural approach, especially for developing cytoskeletal mechanics in adherent cell [32]. Prestressed cable network model is used to model 
the deformability of the adherent cell act in cytoskeleton based on the values observed from living cells and mechanical measurements on isolated act in filaments [32]. Another type of model - open-cell foam model- can be categorized into two types. The first type of open-cell foam model is used to evaluate the mechanical properties and homogenized behaviors of the foam $[37,38,39]$. However, on the basis of this model it is found that the bulk modulus and hydrostatic yield strength of real foams usually are over predicted. To circumvent this drawback, various morphological defects (e.g., non-uniform and wavy cell edges) have to be included [40]. The other one called "super-cell model" has been developed in order to give a better representation of the morphological structure of real foams which usually contain a number of irregular cells, especially Voronoi model, which has been developed by Gibson and co-workers [41,42].

Among microstructural and nanostructural approaches, tensegrity model in conjunction with the finite element method is the widely used. The tensegrity architecture was first described by Buckminster Fuller in 1961 [43]. The basic idea of tensegrity model has explained the stresshardening taking into account internal tensions [44,45].

In some studies researchers concluded that tissues may act continuously at the macroscopic scale, but in fact, they are discrete structural entities when viewed at the scale of cell [46]. The cells also prefer to form attachments heterogeneously that distribute over the cell surface discretely [47]. Tensegrity structure can appropriately model such characteristics. Tensegrity structure has been used here as a computational model of cell-substrate system in order to explain dependency of cell motility on the substrate rigidity. When a cell attaches to a particular surface, geometry of a cell changes as if external forces are applied to the cell membrane. Cellular responses are variable and give rise to a variety of changes of morphology and movement. Cell's morphology and movement that adheres to a substrate is determined by the internal strain energy and interfacial energy. The assumption is that cell can probe its external environment and guide its movement based on the stiffness of the underlying substrate. The hypothesis in this work is that the cell probes the substrate stiffness in different directions and when it finds a direction that leads to the higher stiffness of the substrate this results in the decrease of the internal elastic strain energy. Since the cell, as any structure, prefers to stay in a lower energy state $[48,49]$ this will be its preferred direction of migration. In other words, giving the choice of stiffer or less stiff substrate the cell will adhere to the stiffer substrate and its internal energy will be smaller than if it would adhere to the softer substrate.

On the basis of the above referenced experimental observation a tensegrity based model of cellsubstrate interaction was developed that allows it to mimic how the cell probes the stiffness of a substrate and how different substrate stiffness modified the relative elastic strain energy of the cell. The cytoskeleton of a cell is modeled as a tensegrity structure under prestress and its elastic strain energy is calculated by using finite element method as a function of the stiffness of substrate which it is attached to.

\section{MATERials AND MethodS}

\subsection{TENSEGRITY MODEL}

Tensegrity structure consists of a set of interconnected members carrying compression or tension to provide a mechanical force balance environment, stable volume and shape in the space. The tensegrity structure is used to explain cell motility and shape changes since it provides a comprehensive approach based on a fact that the mechanical integrity is maintained and a self- 
equilibrium is obtained through the contribution of actin filaments that are under tension and microtubules that are under compression [50,51]. A simple tensegrity structure placed on a flat surface is shown in Figure 1. The principle of tensegrity structure is based on the set of isolated components in compression embedded inside of a net of connected tension components in order to separate the compressed members from each other. The role of tension elements carrying "prestress" (i.e., initial stress) is to confer load-supporting capability to the entire structure. Several models based on tensegrity architecture have been used to successfully predict the mechanical responses of whole cells, such as the erythrocytes and viruses [44].

The tensegrity structure representing the cell consists of 30 elements. It is used here to represent a $3 \mathrm{~T} 3$ cell. The $3 \mathrm{~T} 3$ cells come from a cell line established in 1962 by George Todaro and Howard Green [52]. There are 6 pre-compressed struts that represent microtubule members under compressional loads. The rest of the 24 elements are pre-tensed cables that are homologous with microfilament members that carry tensional load. A spring element between nodes 2 and 13 (Figure 1) is used to model an elastic substrate that cytoskeleton is anchored to via focal adhesion. Polydimethylsiloxane (PDMS) is the basic material for cell substrate fabrication in many in-vitro studies and its properties were used to model the substrate. Node 3 is the origin of the coordinate system and node 1 is fixed to the substrate.

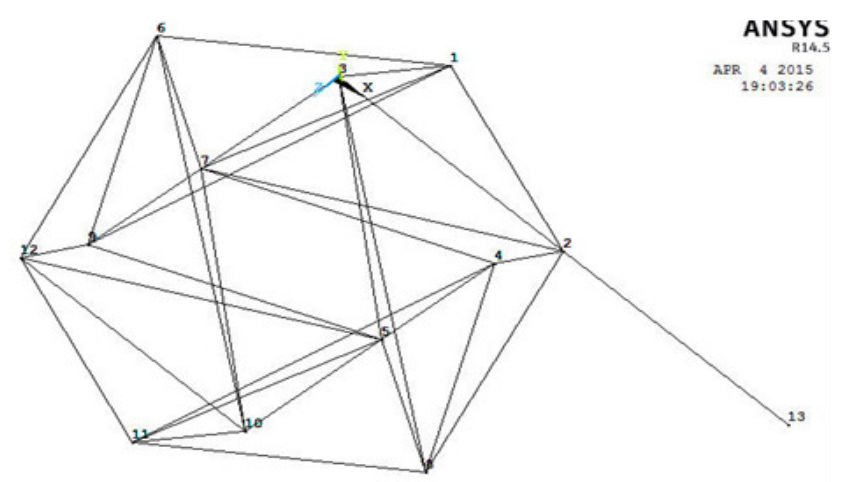

Figure 1 . Tensegrity model with spring element (between nodes 2 and 13 ) representing the substrate stiffness.

Node 3 represents focal adhesion that is linking the substrate and cell. The nodes are allowed to move in three dimensional space without rotation, representing the active movement of a living cell. The length of cables and struts allowed to increase or decrease in this model as a function of the applied prestress and external deformation. The initial length of microtubule and microfilament were selected to be $10 \mu \mathrm{m}$ and $6.12 \mu \mathrm{m}$, respectively. The distance between the socalled "superior plane" (the farthest plane with respect to the X-Y plane) and the "inferior plane" (the nearest plane with respect to the X-Y plane) for un-deformed structure represent the initial height of $8.7 \mu \mathrm{m}$ and these two planes were set to be parallel to each other in the initial state.

\subsection{Material Properties OF The Elements}

To model the cell, we choose Link180, Beam188 and Combine14 as element components from the ANSYS elements library. Link180 and Beam188 are three dimensional truss elements. Link180 element was used to model the cable system, Beam188 element was used to model the 
strut system, the Combine14 element was used to model the substrate stiffness. All components of basic model are treated as elastic. Material properties for microtubules and microfilaments are not known precisely. In Gittes et al. [53] study of the thrice-cycled phosphocellulise-purified tubulin, the Young's modulus was found to be $1.2 \mathrm{GPa}$ for microtubules and $2.6 \mathrm{GPa}$ for microfilaments, the Poisson's ratio for microtubules and microfilaments is 0.3. Tubulin was thought to be specific to eukaryotic cell, 3T3 cells that were obtained from mouse embryo tissue were also a kind of eukaryotic cell. Thus, we use these values as our elements' material properties (Table 1).

Table 1.Modeling and Mechanical Properties of Microtubules and Microfilaments

\begin{tabular}{|l|l|l|l|}
\hline & Microtubules & Microfilaments & Substrate \\
\hline ANSYS Element Type & Link 180 & Beam 188 & Combine 14 \\
\hline Cross-section Area $\left(\boldsymbol{\mu m}^{\mathbf{2}}\right)$ & $1.9 \times 10^{-4}$ & $1.9 \times 10^{-5}$ & \\
\hline Length $(\boldsymbol{\mu m})$ & 10 & 6.12 & 6.12 \\
\hline E $(\mathbf{G P a})$ & 1.2 & 2.6 & \\
\hline $\mathbf{v}$ & 0.3 & 0.3 & \multicolumn{1}{|c|}{ to 1000} \\
\hline Stiffness $(\mathbf{N} / \mathbf{m})$ & & & $\mathrm{N} / \mathrm{m}$ \\
\hline
\end{tabular}

In this study we model attachments of the cell to surfaces with various stiffness values via focal adhesion. Number of different substrates were used for various cell types. For example, Trichet et.al. [54] chose flat PDMS substrate to investigate REF52 fibroblast cell migration response to the stiffness gradients of the substrate. The stiffness of substrate ranges from $0.003 \mathrm{~N} / \mathrm{m}$ to 1.4 $\mathrm{N} / \mathrm{m}$. In another study, Gray et al. [55] have evaluated two different substrates: acrylamide and PDMS. The values of substrate Young's moduli in this study were $2.5 \pm 0.2 \mathrm{MPa}$ and $12 \pm 1 \mathrm{kPa}$ for PDMS material. The cross section area of each material substrate was approximately $10 \mathrm{~mm} \times 50$ $\mathrm{mm}$, while the height was $1 \mathrm{~mm}$. Stiffness can be calculated by using Young's modulus and its structure: $\mathrm{K}=(\mathrm{AE}) / \mathrm{L}$, where $\mathrm{A}=$ cross sectional area, $\mathrm{L}=$ length, and $\mathrm{E}$ is Young's modulus. The stiffness value of PDMS substrate in this study was between $2.6 \mathrm{~N} / \mathrm{m}$ to $540 \mathrm{~N} / \mathrm{m}$. Even though the main material of substrate is PDMS, various concentrations of PDMS lead to substrates with different rigidities. The flexural rigidity of substrate in the present study was assigned in the wide range of $10^{-3}$ to $1000 \mathrm{~N} / \mathrm{m}$ and the discrete values selected for analysis are presented in Table 2. 
Table 2.Values of the Substrate Stiffness used in the Analysis

\begin{tabular}{|c|c|c|c|}
\hline Model & Stiffness (N/m) & Model & Stiffness $(\mathbf{N} / \mathbf{m})$ \\
\hline 1 & 0.001 & 14 & 0.09 \\
\hline 2 & 0.002 & 15 & 0.1 \\
\hline 3 & 0.004 & 16 & 0.2 \\
\hline 4 & 0.006 & 17 & 0.3 \\
\hline 5 & 0.008 & 18 & 0.4 \\
\hline 6 & 0.01 & 19 & 0.5 \\
\hline 7 & 0.02 & 20 & 1 \\
\hline 8 & 0.03 & 21 & 5 \\
\hline 9 & 0.04 & 22 & 10 \\
\hline 10 & 0.05 & 23 & 50 \\
\hline 11 & 0.06 & 24 & 100 \\
\hline 12 & 0.07 & 25 & 500 \\
\hline 13 & 0.08 & 26 & 1000 \\
\hline
\end{tabular}

\subsection{PRESTRESS}

Cellular prestress has a structural importance in resisting extracellular forces and maintaining cell morphology. If there is an external load acting on the structure, the components of structure move relative to one another until attaining a new equilibrium position between cell and external environment. The cytoskeleton prestress plays a key role in mechanotransduction [52]. Gardel et al. [56] assumed that the cells' mechanical properties, especially cell prestress, can influence cells' deformation. The critical importance of prestress makes the model even more similar to the behavior of living cells as the degree of prestress determines the cells stiffness. Therefore, it is necessary to apply prestress forces into cytoskeleton modeling. In this study, prestress values assigned to microfilament and microtubule elements of model are varied to study their effects on the cell strain energy (Table 3). The values represent different cases of the prestress values for the $3 \mathrm{~T} 3$ cell.

Table 3. Range of the Prestress Values used in the Analysis

\begin{tabular}{|c|c|c|}
\hline $\begin{array}{l}\text { Prestress Case } \\
\text { Number }\end{array}$ & Microfilament(pN) & Microtubules(pN) \\
\hline $\mathbf{1}$ & 1.6 & 3.92 \\
\hline $\mathbf{2}$ & 1.0 & 3.92 \\
\hline $\mathbf{3}$ & 2.2 & 3.92 \\
\hline $\mathbf{4}$ & 1.6 & 3.42 \\
\hline $\mathbf{5}$ & 1.6 & 4.42 \\
\hline
\end{tabular}




\subsection{Simulation Procedure}

The gravity and magnetic fields are neglected in the simulation. The model includes possibility of focal adhesion. By extending one of the nodes, the cell can probe and sense the stiffness rigidity of substrate. The strain energy of the cell changes when it extends one of the nodes in order to probe the stiffness of the substrate. This strain energy is computed for number of stiffness values. We model the substrate stiffness by a spring element. In our model, the displacement of the node attached to the substrate and total strain energy of the whole cell will be used to explain the cell preference (from the point of view of minimizing the cell's internal elastic energy) to move to a stiffer substrate.

The simulation process is performed as follows. The first step is to apply prestress forces to the structure. The length of struts or cables will change according to the applied prestress forces. The location of each node in the tensegrity structure is redefined due to the changes of node location in every step. The deformed location of each node in the first step has been stored and used as the new initial location for the second step of the cell simulation. The second step is to give to the node 2 and the other side of the spring element (node 13) an equal displacement in X direction. We apply the same displacement to assure that there is no force in the spring element. Therefore the spring element will not influence the cell energy until the third step. The displacement was selected to be $1 \mu \mathrm{m}$. Since the length of each element in the model is greater than the applied displacement, the shape of the cell will not change significantly due to this displacement. The location of each node has been stored as the initial location for the third step. In the second step, we also get the reaction forces at node 2 which were generated due to the displacement in $\mathrm{X}$ direction. In the third step we fix one side of the spring element (node 13)and apply the reaction force that was calculated in the previous step at the site of node 2 in X direction. In this step, the total strain energy of the cell is calculated and stored in the database. The flow chart of the analysis is presented in Figure 2.

\section{Step 1}

-1. Apply prestress

-2. Calculate the new location of each node

\section{Step 2}

1. Redefine node location

-2. Give Nodes 2 and Node 13 a specific displacement in $\mathrm{X}$ direction

-3. Calculate the new location of each node

-4. Get the reaction force acting at Node 2 .

\section{Step 3}

-1. Redefine node location

-2. Apply opposite of the reaction force at Node 2 that was obtained after Step 2

-3. Fixed one side of spring element (Node 13)

-4. Calculate resulting strain energy of the cell

Figure 2. Flow Chart of the Simulation Process 


\section{RESULTS}

To understand the relationship between preferential direction of cell movement and substrate stiffness during spreading process, the cell model was placed on a particular substrate with a certain stiffness. To evaluate the influence of the prestress on cell preferential direction while cell is anchored on a particular substrate, the model was solved for different values of prestress forces. Simulations were performed on flat substrate which has no topological preference thus there are no other factors that guide the cell motion in a preferential direction, except the substrate stiffness. Hence, the direction of cell motion is defined by the substrate rigidity and cell prestress only.

\subsection{EfFect Of THE SubSTRate Rigidity ON THE Cell's STRAin ENERgY}

By running the model with ANSYS Mechanical APDL solver, the tendency of cell movement in the substrates with different rigidities was analyzed. To explore the relationship between substrate stiffness and cell directional movement with the certain prestress values for the cable (representing microtubules) and strut (representing microfilaments) elements, number of different values of substrate stiffness had been used in the study. For the first case the prestress values of the model structure were selected to be $1.6 \mathrm{pN}$ for microfilaments and $3.92 \mathrm{pN}$ for microtubules, while the substrate rigidity was selected to be relatively small, $0.001 \mathrm{~N} / \mathrm{m}$ (Case 1$)$.

The displacements of each node were around $0.1 \mu \mathrm{m}$ after applying the prestress. Since lengths of the cables and the struts are around $1-5 \mu \mathrm{m}$, the location of each node changed very little after the first step (application of prestress). The deformation of cell structure after the second step (nodes 2 and 13 were given a specific, $1 \mu \mathrm{m}$ displacement in $\mathrm{X}$ direction) is shown in Figure 3. It is obvious that the node 2 and node 13 moved the same distance. The spring element (between node 2 and node 13) has no internal force due to this movement.

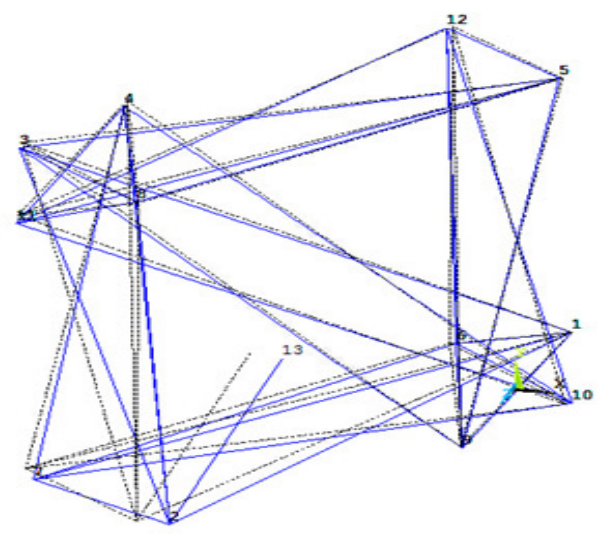

Figure 3.Comparison of node displacements due to the $2^{\text {nd }}$ step. It is obvious that the segment 2-13 just translated but did not change its length. Dotted lines represent original location, solid - after the $2^{\text {nd }}$ step.

The third step simulating attachment of the cell's filopodia to the substrate results in the new configuration. The comparison of cell's geometry before and after the third step has been shown in Figure 4. The dash lines show the geometry before the third step, while the solid lines shows 
the geometry after the third step. For the third step, the node 13 is located at the same location since the node 13 (one side of the spring element) was fixed to model the cell's adhesion to the substrate. The node 2 displaced $0.878 \mu \mathrm{m}$ in $\mathrm{X}$ direction since the substrate rigidity is relatively very small, just $0.001 \mathrm{~N} / \mathrm{m}$ (Figure4). Softer spring element represents softer substrate.

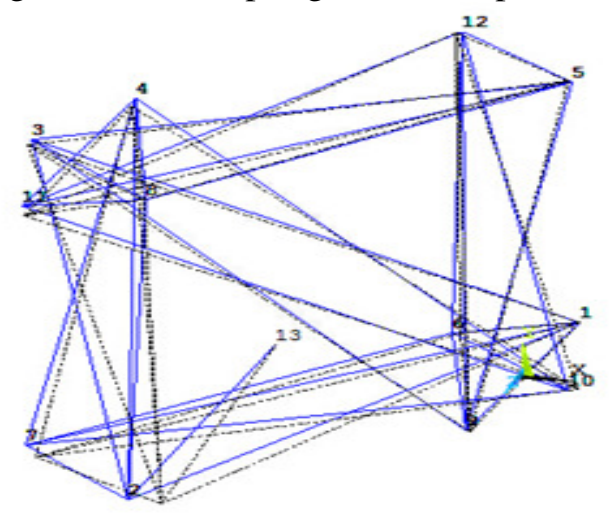

Figure 4. Comparison of node displacements due to the $3^{\text {rd }}$ Step

The displacement of node 2 and strain energy of cell has been influenced by substrate stiffness. The simulation results (cell's strain energy and node 2 displacement) of models with various values of the substrate stiffness for the first case of prestress values are shown in Appendix (Table A1).

The displacement of the node 2 in $\mathrm{X}$ direction as a function of substrate stiffness is shown in Figure 5. It is obvious that the displacement of node 2 is a function of substrate stiffness. With the substrate stiffness increases, the displacement of node 2 decreases significantly.

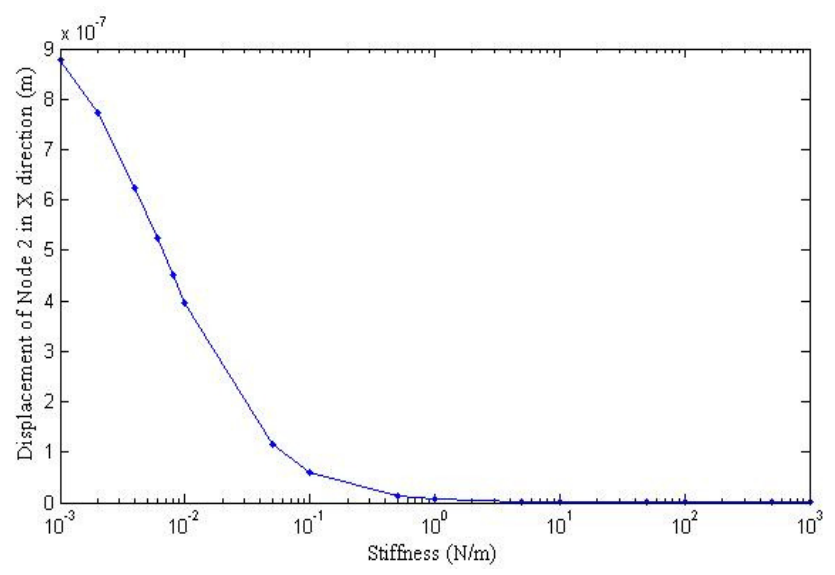

Figure 5. Displacement of Node 2 after the $3^{\text {rd }}$ Step in $X$ direction for Substrate Stiffness in the range of $10^{-3} \mathrm{~N} / \mathrm{m}$ to $10^{3} \mathrm{~N} / \mathrm{m}$ (Prestress Case 1 ) 
International Journal of Biomedical Engineering and Science (IJBES), Vol. 3, No. 1, January 2016

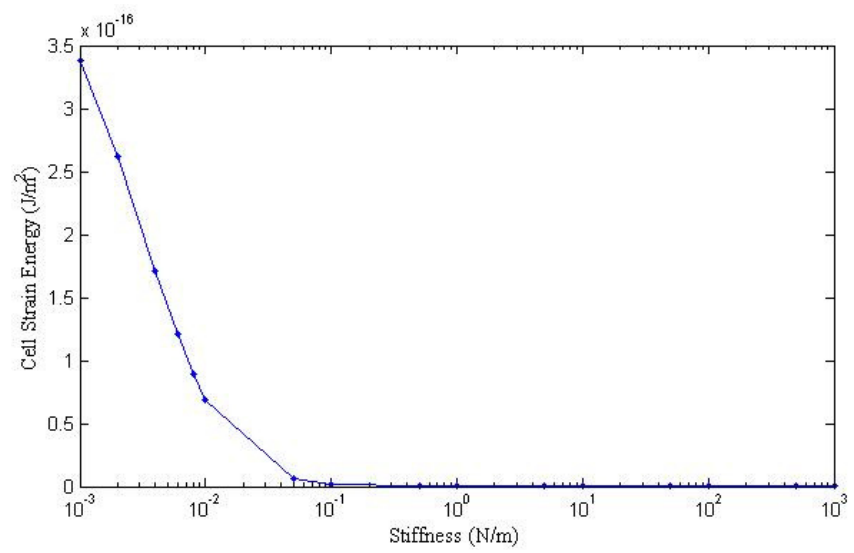

Figure 6. Cell Strain Energy for Substrate Stiffness in the range of $10^{-3} \mathrm{~N} / \mathrm{m}$ to $10^{3} \mathrm{~N} / \mathrm{m}$ (Prestress Case 1)

The total cell strain energy that includes elastic energies of all cell elements is presented in Figure 6. For the substrate stiffness values over $0.5 \mathrm{~N} / \mathrm{m}$, the cell strain energy changes is hard to visualize thus they are shown in the following Figures. Figure 7 shows the results for the stiffness range of $0.01 \mathrm{~N} / \mathrm{m}$ to $0.1 \mathrm{~N} / \mathrm{m}$, while Figure 8 shows the results for the stiffness range of $0.1 \mathrm{~N} / \mathrm{m}$ to $1 \mathrm{~N} / \mathrm{m}$.

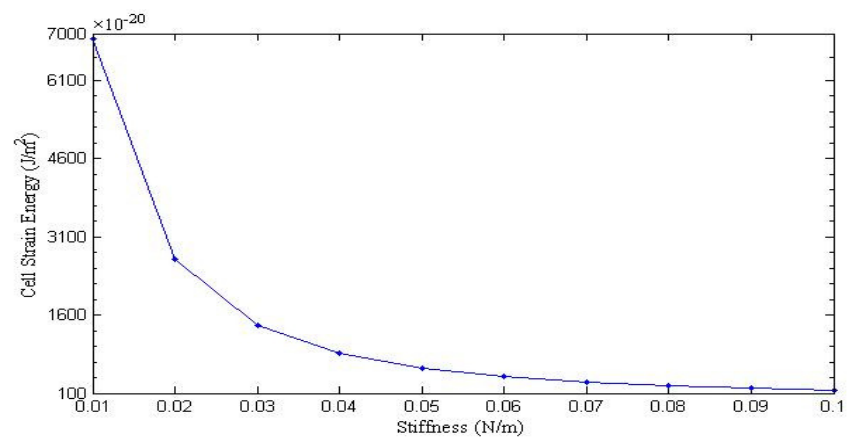

Figure 7. Cell Strain Energy for Substrate Stiffness in the range of $0.01 \mathrm{~N} / \mathrm{m}$ to $0.1 \mathrm{~N} / \mathrm{m}$ (Prestress Case 1)

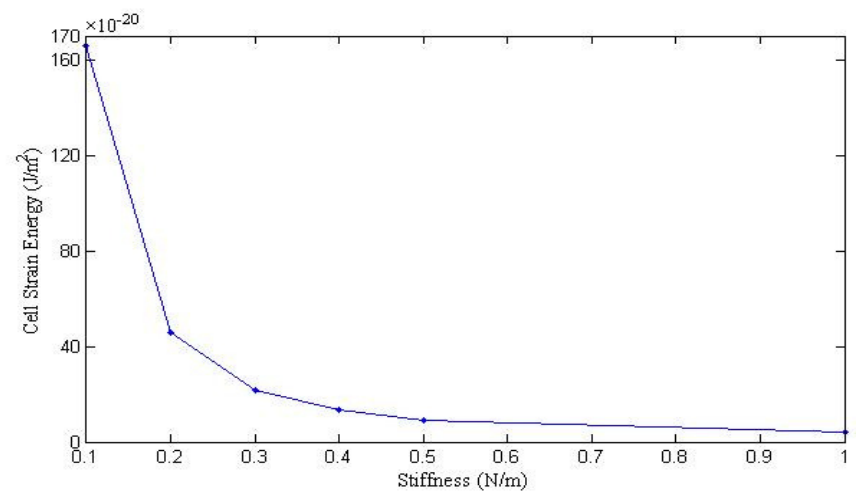

Figure 8. Cell Strain Energy for Substrate Stiffness in the range of $0.1 \mathrm{~N} / \mathrm{m}$ to $1 \mathrm{~N} / \mathrm{m}$ (Prestress Case 1). 
The obtained results clearly show the tendency of the cell's elastic strain energy decrease with the increase of the substrate stiffness. The results (Figure 5) also indicate that the decrease in the node 2 displacement correlates with the decrease in the elastic strain energy.

With higher substrate rigidity, the cell tends to keep its morphology in a lower energy state. This result supports the hypothesis in this work that the cell probes the substrate stiffness and when it finds a higher stiffness of the substrate this results in the decrease of the cell's internal strain energy. In a sum, the strain energy of cell structure decreases when substrate stiffness increases and this may explain why cell tends to move towards the stiff substrate instead of the soft one.

\subsection{Influence Ofthe Prestress On The Cell's Elastic energy}

To explore how the prestress influences cell strain energy and its preferable movement, we analyzed several cases of prestress forces with different substrate rigidities. Since there are two elements (struts and cables) loaded by prestress, we investigate the influence of each of these elements separately. First, we keep the prestress of strut element constant and change the prestress of the cable elements. In this situation case 1, case 2 and case 3 have been studied with the prestress force of strut element equals to $3.92 \mathrm{pN}$ while the prestress force values of cable element were selected to be $1.6 \mathrm{pN}, 1.0 \mathrm{pN}$, and $2.2 \mathrm{pN}$, respectively. Then, we keep the cable elements' prestress values constant and change the prestress of strut element. The strut element prestress values were $3.92 \mathrm{pN}, 3.42 \mathrm{pN}$, and $4.42 \mathrm{pN}$, respectively. These values have been explored in the cases 4 and 5. The substrate stiffness values range from $0.004 \mathrm{~N} / \mathrm{m}$ to $1000 \mathrm{~N} / \mathrm{m}$. The simulation results for models with various values of the substrate stiffness for all cases of prestress are shown in Appendix (Table A2.) Figure 9 and Figure 10 show the tendency of cell strain energy for the cases 1-3 and of case 1, case 4 and case 5, separately. In all prestress cases, the strain energy of the cell decreases when substrate rigidity increases. The prestress does not change the qualitative behavior of the strain energy of a cell.

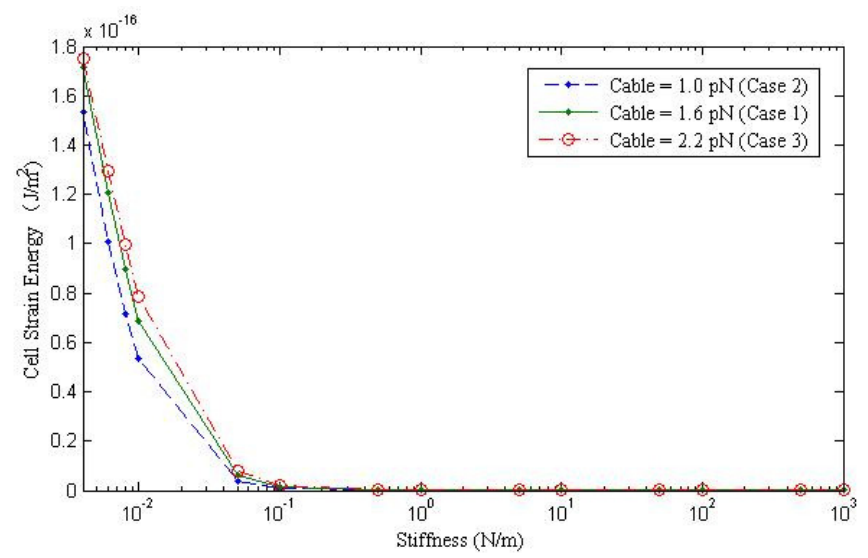

Figure 9. Cell Strain Energy with Prestress Cases 1, 2, and 3. Prestress of the strut element equals to 3.92 $\mathrm{pN}$. 


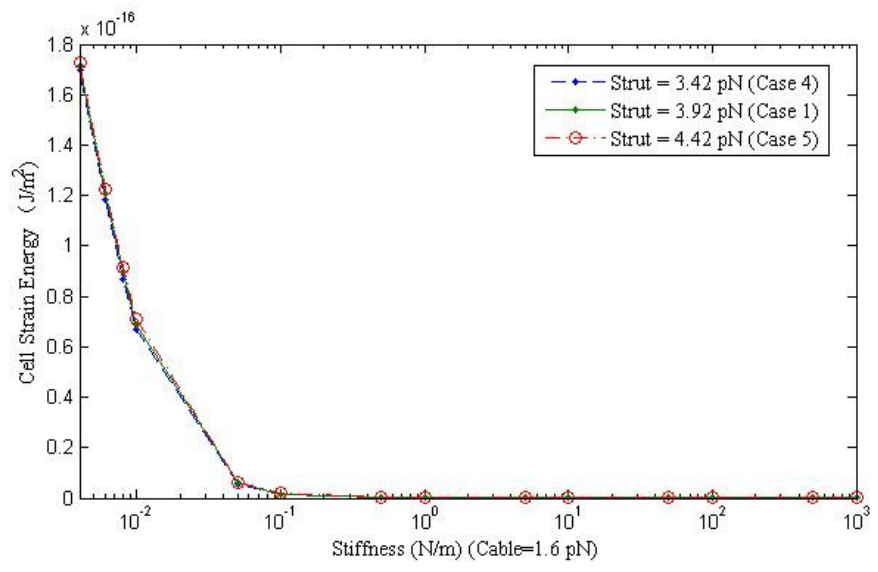

Figure 10. Cell Strain Energy with Prestress Cases 1, 4, and 5. Prestress of the cable element equals to 1.6 $\mathrm{pN}$.

The differences in values of strain energy for cases 1-3 with three different cable prestress are significant, but qualitatively they follow the same pattern (Figure 9). The increasing cable prestress value gives rise to increase of the strain energy of cell. With substrate stiffness increase, the strain energy of the cell tends to decrease, the change of prestress of cable element does not change the behavior pattern of the strain energy.

The differences of strain energy due to three different strut prestresses are smaller (Figure 10). Hence, the change of prestress value does not change behavior pattern of the strain energy: the strain energy will decrease with substrate stiffness increase.

\section{DISCUSSION}

This study is based on the assumption that the cell can guide its movement by probing the substrate's rigidity. From the mechanistic point of view it is preferable to be in the lower energetic state, therefore we assume that while probing the substrate stiffness in different directions the cell will find a direction that results in the decrease of the cell's internal elastic energy and will move in this direction. Experimental observations confirm that cells can probe their environment through lamellipodial extensions [57,58] and guide their movement according to the substrate stiffness $[59,60]$. As the results of the simulation show when the substrate rigidity is increasing, the cell has smaller internal strain energy, leading to directed movement to the rigid substrate. Conversely, as substrate becomes softer, the strain energy of cell structure increases. It is known $[16,24]$ that mechanical force generated between substrate and cell regulates the deformation and migration of the cell. This is to be expected in an active sensing system of cell-substrate system, because the force or deformation will influence the cell and substrate interactions. Ni and Chiang [48] developed a mathematical model to demonstrate how substrate rigidity influences cell migration and morphology. The cell was assumed as two-dimensional flat elastic membrane while the substrate was assumed as three-dimensional elastic structure. They demonstrated that the internal elastic strain energy of cell generated by intracellular and extracellular forces destabilizes the cell morphology and migration activity. In the other words, with substrate stiffness increase the lower energy state of cell can be reached. These observations confirm our results based on the tensegrity model of cell movement. The related experimental results were presented by Lo, Wang, Dembo, and Wang [10] in the study of National Institutes of Health 3T3 cells and culturing them 
on flexible polyacrylamide sheets coated with type I collagen. In this study, they controlled material concentrations to create high and low rigidity regions in one substrate sheet. The result showed that the overall rate migration of cells increased significantly as the cell crossed the rigidity boundary from the soft to the stiff side. The cells' preferential migration direction was toward the stiffer region. This experimental observation clearly confirms the results obtained here by the tensegrity model.

The physicochemical and biochemical signals of external environment can be detected and transduced into intracellular responses, which be capable of affecting the cell behavior via focal adhesion. Cells can sense substrate stiffness by extending a probe in particular direction, and attaching itself to the surface. On stiff substrate, cell has smaller displacement of focal adhesion since the reaction force is a function of the substrate stiffness. The stronger mechanical feedback may then lead to the stress-sensitive ion channels' activations [61] or tension-sensitive proteins' conformational changes. The focal adhesions form easily and lead to more stable system between the cell and substrate. Therefore, the cells prefer to move to stiff substrate rather than soft substrate.

In addition to substrate rigidity, we have explored the possibility that prestress in the cell itself also regulates the cell movement. Although the strain energy for each prestress case is different, the change of prestress value does not change behavior pattern of the strain energy: cell's strain energy will decrease when substrate stiffness increases.

The simulation results provide direct evidences for the guidance of the cell migration by substrate rigidity and prestress based on the minimization of the internal elastic energy. Related phenomena have been reported in literature review in recent decades. In reality, the cell movement is probably guided by a complex interplay among chemical and physical signals, which may include substrate rigidity as well as forces generated by other activities: fluid shear, cell-cell interactions, etc.

\section{Conclusions}

A computational model based on tensegrity structure of a cell attached to a substrate was analyzed. According to the model, the stiffer is the substrate, the lower is the strain energy and the smaller is the deformation of cell structure. When prestress in a cell structure is increased, the strain energy of the cell is increased. Since connections between cells with low strain energy and substrates are more stable, they would increase the cells' functional efficiencies and focal adhesions' formations [62]. Consequently, this would result into a directional cell motion from softer region to stiffer region on the substrate with varying rigidity.

The substrate rigidity and cell prestress play a certain role in cell directional movement. The change of prestress value does not change qualitative behavior of the strain energy: cell's elastic strain energy will decrease with substrate stiffness increase. With substrate rigidity increase, the strain energy of cell structure decreases. This tendency explains that within a substrate with various rigidity, cell prefers to move towards stiffer regions as it was experimentally observed.

The computational results show that the cell strain energy changes due to the extracellular environments and cellular prestress. By analyzing the cell response to different prestress values and substrate rigidity, it is shown that cells will move towards the position where their internal elastic energy is lower, which supports the available experimental data. 
International Journal of Biomedical Engineering and Science (IJBES), Vol. 3, No. 1, January 2016

\section{ACKNOWLEDGEMENT}

I would like to thank Mrs. Jie Sheng for help in running the ANSYS code.

\section{REFERENCES}

[1] David I. Walsh III, Mark L. Lalli, Juliette M. Kassas, Anand R. Asthagiri, \& Shashi K. Murthy, (2105) "Cell Chemotaxis on Paper for Diagnostics", Anal.Chem, 87(11), 5505-5510.

[2] Lo, C. M., Wang, H. B., Dembo, M., \& Wang, Y. (2000) "Cell Movement Is Guided by the Rigidity of the Substrate", Biophys J., 79(1), 144-52.

[3] Kazuo Umemura, Toru Miyabayashi, Hisao Taira, Akira Suzuki, Yoshikazu Kumashiro, Teruo Okano, \& Shigeki Mayama, (2015) "Use of a microchamber for analysis of thermal variation of the gliding phenomenon of single Navicula pavillardii cells", Eur Biophys J., 44(3), 113-119.

[4] Curtze S, Dembo M, Miron M, \& Jones DB, (2004) "Dynamic changes in traction forces with DC electric field in osteoblast-like cells. J Cell Sci., 117 (Pt 13):2721-2729. Epub 2004 May 18.

[5] E. P. Yalcintas, J. Hu, Y. Liu \& A. Voloshin, (2014) "Modeling Cell Spreading and Alignment on Micro-Wavy Surfaces", Computer Modeling in Engineering and Science (CMES), 98 (2), 151-180; doi:10.3970/cmes.2014.098.151

[6] Stamenović, D., \& Ingber, D. E. (2009) "Tensegrity-guided self assembly: from molecules to living cells", Soft Matter, 5(6), 1137-1145.

[7] Discher, D. E., Janmey, P., \& Wang, Y. L. (2005) "Tissue cells feel and respond to the stiffness of their substrate", Science, 310(5751), 1139-1143.

[8] Georges, P. C., \& Janmey, P. A. (2005) "Cell type-specific response to growth on soft materials", Journal of applied physiology, 98(4), 1547-1553.

[9] Wang, N., Butler, J. P., \& Ingber, D. E. (1993) "Mechanotransduction across the cell surface and through the cytoskeleton", Science, 260 (5111), 1124-1127.

[10] Chicurel, M. E., Chen, C. S., \& Ingber, D. E. (1998) "Cellular control lies in the balance of forces", Current opinion in cell biology, 10(2), 232-239.

[11] Ghosh, K., Pan, Z., Guan, E., Ge, S., Liu, Y., Nakamura, T., Ren, X. D., Rafailovich, M., \& Clark, R. A. (2007)"Cell adaptation to a physiologically relevant ECM mimic with different viscoelastic properties", Biomaterials, 28(4), 671-679.

[12] Engler, A. J., Sen, S., Sweeney, H. L., \& Discher, D. E. (2006) "Matrix elasticity directs stem cell lineage specification", Cell, 126(4), 677-689.

[13] Guo, W. H., Frey, M. T., Burnham, N. A., \& Wang, Y. L. (2006) "Substrate rigidity regulates the formation and maintenance of tissues", Biophysical journal, 90(6), 2213-2220.

[14] Jiang, G., Huang, A. H., Cai, Y., Tanase, M., \& Sheetz, M. P. (2006) "Rigidity sensing at the leading edge through $\alpha$ V $\beta 3$ integrins and RPTP $\alpha$ ", Biophysical journal, 90(5), 1804-1809.

[15] Lo, C. M., Wang, H. B., Dembo, M., \& Wang, Y. L. (2000) "Cell movement is guided by the rigidity of the substrate", Biophysical journal, 79(1), 144-152.

[16] Sochol, R. D., Higa, A. T., Janairo, R. R., Li, S., and Lin, L. (2011) "Unidirectional mechanical cellular stimuli via micropost array gradients", Soft Matter, 7(10), 4606-4609.

[17] McGarry, J. G., \& Prendergast, P. J. (2004) "A three-dimensional finite element model of an adherent eukaryotic cell", Eur Cell Mater, 7, 27-33.

[18] Chen, T. J., Wu, C. C., Tang, M. J., Huang, J. S., \& Su, F. C. (2010) "Complexity of the tensegrity structure for dynamic energy and force distribution of cytoskeleton during cell spreading", PloS one, 5(12), e14392.

[19] Parameswaran, H., Lutchen, K. R., \& Suki, B. (2014) "A computational model of the response of adherent cells to stretch and changes in substrate stiffness", Journal of Applied Physiology, 116(7), 825-834.

[20] Flaherty, B., McGarry, J. P., \& McHugh, P. E. (2007) "Mathematical models of cell motility", Cell biochemistry and biophysics, 49(1), 14-28.

[21] Wendling, S., Oddou, C., \& Isabey, D. (1999) "Stiffening response of a cellular tensegrity model", Journal of theoretical biology, 196(3), 309-325.

[22] Coughlin, M. F., \& Stamenovic, D. (1998) "A tensegrity model of the cytoskeleton in spread and 
International Journal of Biomedical Engineering and Science (IJBES), Vol. 3, No. 1, January 2016

round cells', Journal of biomechanical engineering, 120(6), 770-777.

[23] Chen, C. S., Mrksich, M., Huang, S., Whitesides, G. M., \& Ingber, D. E. (1997) "Geometric control of cell life and death", Science, 276(5317), 1425-1428.

[24] Bernstein, L. R., \& Liotta, L. A. (1994) "Molecular mediators of interactions with extracellular matrix components in metastasis and angiogenesis", Current opinion in oncology, 6(1), 106.

[25] Friedl, P., Zänker, K. S., \& Bröcker, E. B. (1998) "Cell migration strategies in 3-D extracellular matrix: differences in morphology, cell matrix interactions, and integrin function", Microscopy research and technique, 43(5), 369-378.

[26] Yeung, T., Georges, P. C., Flanagan, L. A., Marg, B., Ortiz, M., Funaki, M., Zahir, N., Ming, W. Y., Weaver, V., \& Janmey, P. A. (2005) "Effects of substrate stiffness on cell morphology, cytoskeletal structure, and adhesion", Cell motility and the cytoskeleton, 60(1), 24-34.

[27] Li, S., Guan, J. L., \& Chien, S. (2005) "Biochemistry and biomechanics of cell motility", Annu. Rev. Biomed. Eng., 7, 105-150.

[28] Sheetz, M. P., Felsenfeld, D. P., \& Galbraith, C. G. (1998) "Cell migration: regulation of force on extracellular-matrix-integrin complexes", Trends in cell biology, 8(2), 51-54.

[29] Georges, P. C., Miller, W. J., Meaney, D. F., Sawyer, E. S., \& Janmey, P. A. (2006) "Matrices with compliance comparable to that of brain tissue select neuronal over glial growth in mixed cortical cultures", Biophysical journal, 90(8), 3012-3018.

[30] Saez, A., Ghibaudo, M., Buguin, A., Silberzan, P., \& Ladoux, B. (2007) "Rigidity-driven growth and migration of epithelial cells on microstructured anisotropic substrates", Proceedings of the National Academy of Sciences, 104(20), 8281-8286.

[31] Rabineau, M., Flick, F., Mathieu, E., Tu, A., Senger, B., Voegel, J.C., Lavalle, P., Schaaf, P., Freund, J.N., Haikel,Y., Vautier, D. (2015) "Cell guidance into quiescent state through chromatin remodeling induced by elastic modulus of substrate", Biomaterials, 37(1), 144-155.

[32] Yeung, A., \& Evans, E. (1989) "Cortical shell-liquid core model for passive flow of liquid-like spherical cells into micropipets", Biophysical journal, 56(1), 139-149.

[33] Coughlin, M. F., \& Stamenović, D. (2003) "A prestressed cable network model of the adherent cell cytoskeleton”, Biophysical journal, 84(2), 1328-1336.

[34] Karcher, H., Lammerding, J., Huang, H., Lee, R. T., Kamm, R. D., \& Kaazempur-Mofrad, M. R. (2003)"A three-dimensional viscoelastic model for cell deformation with experimental verification", Biophysical journal, 85(5), 3336-3349.

[35] Shieh, A. C., \& Athanasiou, K. A. (2003) "Principles of cell mechanics for cartilage tissue engineering", Annals of biomedical engineering, 31(1), 1-11.

[36] Lim, C. T., Zhou, E. H., \& Quek, S. T. (2006) " Mechanical models for living cells - a review", Journal of biomechanics, 39(2), 195-216.

[37] Gan, Y. X., Chen, C., \& Shen, Y. P. (2005) "Three-dimensional modeling of the mechanical property of linearly elastic open cell foams", International Journal of Solids and Structures, 42(26), 66286642.

[38] Gong, L., \& Kyriakides, S. (2005)" Compressive response of open cell foams Part II: Initiation and evolution of crushing", International Journal of Solids and Structures, 42(5), 1381-1399.

[39] Gong, L., Kyriakides, S., \& Jang, W. Y. (2005) “Compressive response of open-cell foams. Part I: Morphology and elastic properties", International Journal of Solids and Structures, 42(5), 13551379.

[40] Chen, C., Lu, T. J., \& Fleck, N. A. (1999) "Effect of imperfections on the yielding of twodimensional foams", Journal of the Mechanics and Physics of Solids, 47(11), 2235-2272.

[41] Silva, M. J., Hayes, W. C., \& Gibson, L. J. (1995) "The effects of non-periodic microstructure on the elastic properties of two-dimensional cellular solids", International Journal of Mechanical Sciences, 37(11), 1161-1177.

[42] Simone, A. E., \& Gibson, L. J. (1998) "The effects of cell face curvature and corrugations on the stiffness and strength of metallic foams", Acta Materialia, 46(11), 3929-3935.

[43] Fuller, B. (1961) “Tensegrity”, Portfolio Artnews Annual 4, 112-127.

[44] Ingber, D. E. (1993) "Cellular tensegrity: defining new rules of biological design that govern the cytoskeleton", Journal of cell science, 104, 613-613.

[45] Luo, Y., Xu, X., Lele, T., Kumar, S., \& Ingber, D. E. (2008) “A multi-modular tensegrity model of an 
International Journal of Biomedical Engineering and Science (IJBES), Vol. 3, No. 1, January 2016

actin stress fiber", Journal of biomechanics, 41(11), 2379-2387.

[46] Sander, E. A., Stylianopoulos, T., Tranquillo, R. T., \& Barocas, V. H. (2009) "Image-based multiscale modeling predicts tissue-level and network-level fiber reorganization in stretched cellcompacted collagen gels", Proceedings of the National Academy of Sciences, 106(42), 1767517680.

[47] Cukierman, E., Pankov, R., Stevens, D. R., \& Yamada, K. M. (2001) "Taking cell-matrix adhesions to the third dimension," Science, 294(5547), 1708-1712.

[48] Ni, Y., \& Chiang, M. Y. (2007) "Cell morphology and migration linked to substrate rigidity", Soft Matter, 3(10), 1285-1292.

[49] Yalcintas, E. P., Hu, J., Liu, Y., \& Voloshin, A. (2014) "Modeling Cell Spreading and Alignment on Micro-Wavy Surfaces”, CMES: Computer Modeling in Engineering \& Sciences, 98(2), 151-180.

[50] Ingber, D. E. (2003) “Tensegrity I, Cell structure and hierarchical systems biology”, Journal of Cell Science, 116(7), 1157-1173.

[51] Ingber, D. E. (2008) “Tensegrity and mechanotransduction”, Journal of bodywork and movement therapies, 12(3), 198-200.

[52] Todaro, G. J., \& Green, H. (1963) "Quantitative studies of the growth of mouse embryo cells in culture and their development into established lines", The Journal of cell biology, 17(2), 299-313.

[53] Gittes, F., Mickey, B., Nettleton, J., \& Howard, J. (1993) "Flexural rigidity of microtubules and actin filaments measured from thermal fluctuations in shape", The Journal of cell biology, 120(4), 923934.

[54] Trichet, L., Le Digabel, J., Hawkins, R. J., Vedula, S. R. K., Gupta, M., Ribrault, C., Hersen, P., Voituriez, R., \& Ladoux, B. (2012) "Evidence of a large-scale mechanosensing mechanism for cellular adaptation to substrate stiffness," Proceedings of the National Academy of Sciences, 109(18), 6933-6938.

[55] Gray, D. S., Tien, J., \& Chen, C. S. (2003) "Repositioning of cells by mechanotaxis on surfaces with micropatterned Young's modulus", Journal of biomedical materials research Part A, 66(3), 605-614.

[56] Gardel, M. L., Nakamura, F., Hartwig, J. H., Crocker, J. C., Stossel, T. P., \& Weitz, D. A. (2006) "Prestressed F-actin networks cross-linked by hinged filamins replicate mechanical properties of cells", Proceedings of the National Academy of Sciences of the United States of America, 103(6), 1762-1767.

[57] Pelham, R. J., \& Wang, Y. L. (1999) "High resolution detection of mechanical forces exerted by locomoting fibroblasts on the substrate", Molecular biology of the cell, 10(4), 935-945.

[58] Galbraith, C. G., Yamada, K. M., \& Galbraith, J. A. (2007) "Polymerizing actin fibers position integrins primed to probe for adhesion sites", Science, 315(5814), 992-995.

[59] Hadjipanayi, E., Mudera, V., \& Brown, R. A. (2009) "Guiding cell migration in 3D: a collagen matrix with graded directional stiffness", Cell motility and the cytoskeleton, 66(3), 121-128.

[60] Wong, J. Y., Velasco, A., Rajagopalan, P., \& Pham, Q. (2003) "Directed movement of vascular smooth muscle cells on gradient-compliant hydrogels", Langmuir, 19(5), 1908-1913.

[61] Lee, J., Ishihara, A., Oxford, G., Johnson, B., \& Jacobson, K. (1999) "Regulation of cell movement is mediated by stretch-activated calcium channels", Nature, 400(6742), 382-386.

\section{Authors Bio}

\section{Arkady Voloshin}

Arkady Voloshin is a Professor of Mechanical Engineering and Mechanics and Bioengineering Program at Lehigh University. His professional interests include modeling of the cell motility based on the surface topology and mechanical properties, study of the effects of dynamic excitation on the human musculoskeletal system and cell behavior. 
International Journal of Biomedical Engineering and Science (IJBES), Vol. 3, No. 1, January 2016

\section{APPENDIX}

Table A1. Strain Energy and Node 2 Displacement in X Direction for the Substrate Stiffness in the range of $10^{-3} \mathrm{~N} / \mathrm{m}$ to $10^{3} \mathrm{~N} / \mathrm{m}$ (Prestress Case 1 ).

\begin{tabular}{|l|l|l|l|}
\hline Model & $\begin{array}{l}\text { Substrate } \\
\text { Stiffness (N/m) }\end{array}$ & $\begin{array}{l}\text { Displacement } \\
\text { of Node 2 in } \\
\text { direction } \mathbf{( m )}\end{array}$ & $\begin{array}{l}\text { Strain } \\
\left(\times \mathbf{1 0}^{-20} \mathbf{J}^{\mathbf{m}} \mathbf{m}^{\mathbf{2}}\right)\end{array}$ \\
\hline $\mathbf{1}$ & 0.001 & $8.78 \times 10^{-7}$ & 33800 \\
\hline $\mathbf{2}$ & 0.002 & $7.73 \times 10^{-7}$ & 26200 \\
\hline $\mathbf{3}$ & 0.004 & $6.25 \times 10^{-7}$ & 17130 \\
\hline $\mathbf{4}$ & 0.006 & $5.24 \times 10^{-7}$ & 12060 \\
\hline $\mathbf{5}$ & 0.008 & $4.51 \times 10^{-7}$ & 8940 \\
\hline $\mathbf{6}$ & 0.01 & $3.96 \times 10^{-7}$ & 6900 \\
\hline $\mathbf{7}$ & 0.05 & $1.15 \times 10^{-7}$ & 585 \\
\hline $\mathbf{8}$ & 0.1 & $6.11 \times 10^{-8}$ & 166.0 \\
\hline $\mathbf{9}$ & 0.5 & $1.28 \times 10^{-8}$ & 9.31 \\
\hline $\mathbf{1 0}$ & 1 & $6.46 \times 10^{-9}$ & 3.90 \\
\hline $\mathbf{1 1}$ & 5 & $1.30 \times 10^{-9}$ & 2.14 \\
\hline $\mathbf{1 2}$ & 10 & $6.50 \times 10^{-10}$ & 2.09 \\
\hline $\mathbf{1 3}$ & 50 & $1.30 \times 10^{-10}$ & 2.07 \\
\hline $\mathbf{1 4}$ & 100 & $6.51 \times 10^{-11}$ & 2.07 \\
\hline $\mathbf{1 5}$ & 500 & $1.30 \times 10^{-11}$ & 2.07 \\
\hline $\mathbf{1 6}$ & 1000 & $6.49 \times 10^{-12}$ & 2.07 \\
\hline & & & \\
\hline
\end{tabular}


International Journal of Biomedical Engineering and Science (IJBES), Vol. 3, No. 1, January 2016

Table A2. Cell elastic strain energy for the substrate stiffness in the range of $0.004 \mathrm{~N} / \mathrm{m}$ to $1000 \mathrm{~N} / \mathrm{m}$ for various prestress cases.

\begin{tabular}{|c|c|c|c|c|c|c|}
\hline \multirow{2}{*}{ Model } & \multirow{2}{*}{$\begin{array}{c}\text { Stiffness } \\
(\mathbf{N} / \mathbf{m})\end{array}$} & \multicolumn{5}{|c|}{$\begin{array}{c}\text { Strain Energy } \\
\left(\times \mathbf{1 0}^{-21} \mathbf{J} / \mathbf{m}^{\mathbf{2}}\right)\end{array}$} \\
\cline { 3 - 7 } & & Case 1 & Case 2 & Case 3 & Case 4 & Case 5 \\
\hline $\mathbf{1}$ & 0.004 & 171300 & 153400 & 175200 & 169600 & 172600 \\
\hline $\mathbf{2}$ & 0.006 & 120600 & 101000 & 129400 & 118100 & 122700 \\
\hline $\mathbf{3}$ & 0.008 & 89400 & 71500 & 99400 & 87000 & 91600 \\
\hline $\mathbf{4}$ & 0.01 & 69000 & 53300 & 78800 & 66700 & 71000 \\
\hline $\mathbf{5}$ & 0.05 & 5850 & 3820 & 7750 & 5500 & 6200 \\
\hline $\mathbf{6}$ & 0.1 & 1661 & 1050 & 2280 & 1552 & 1767 \\
\hline $\mathbf{7}$ & 0.5 & 93.1 & 52.3 & 147.0 & 86.8 & 99.5 \\
\hline $\mathbf{8}$ & 1 & 39.0 & 18.90 & 71.4 & 36.5 & 41.7 \\
\hline $\mathbf{9}$ & 5 & 21.4 & 8.07 & 46.7 & 20.1 & 22.8 \\
\hline $\mathbf{1 0}$ & 10 & 20.9 & 7.73 & 46.0 & 19.60 & 22.3 \\
\hline $\mathbf{1 1}$ & 50 & 20.7 & 7.62 & 45.7 & 19.44 & 22.1 \\
\hline $\mathbf{1 2}$ & 100 & 20.7 & 7.61 & 45.7 & 19.43 & 22.1 \\
\hline $\mathbf{1 3}$ & 500 & 20.7 & 7.61 & 45.7 & 19.33 & 22.1 \\
\hline $\mathbf{1 4}$ & 1000 & 20.7 & 7.61 & 45.7 & 19.33 & 22.1 \\
\hline
\end{tabular}

